\title{
Biodegradation of hydrocarbons in soil by microbial consortium
}

\begin{abstract}
The bioremediation of hydrocarbon in contaminated soils by mixed cultures of hydrocarbondegrading bacteria was investigated. The mixtures or consortia of bacteria, denoted as Consortium 1 and Consortium 2 consisted of 3 and 6 bacterial strains, respectively. Bacterial strains used in this study were from the Center for Research in Enzymes and Microbiology (CREAM) collection of strains, at Universiti Putra Malaysia, and were isolated from hydrocarbon-contaminated soil samples by enrichments on either crude oil or individual hydrocarbons as the sole carbon source. The strains were selected based on the criteria that they were able to display good growth in crude oil, individual hydrocarbon compounds or both. Their ability to degrade hydrocarbon contamination in the environment was investigated using soil samples that were contaminated with diesel, crude oil or engine oil. Consortium 2, which consisted of 6 bacterial strains, was more efficient at removing the medium- and long-chain alkanes in the diesel-contaminated soil compared to Consortium 1. Further, Consortium 2 could effectively remove the medium- and long-chain alkanes in the engine oil such that the alkanes were undetectable after a 30-day incubation period. Consortium 2 consisted predominantly of Bacillus and Pseudomonas spp.
\end{abstract}

Keyword: Biodegradation, Hydrocarbons, Microbial consortium, Pseudomonas sp., Bacillus sp. 